\title{
Effect of UV Pretreatment on the Nanopore Formation within Organosilicate Thin Films
}

\author{
Suhan Kim, ${ }^{a}$ Yi-Yeol Lyu, ${ }^{a}$ Junhee Hahn, ${ }^{\text {b }}$ and Kookheon Char $^{\text {a,z }}$ \\ ${ }^{a}$ School of Chemical and Biological Engineering, NANO Systems Institute-National Core Research Center, \\ Seoul National University, Seoul 151-744, Korea \\ ${ }^{b}$ Division of Chemical Metrology and Materials Evaluation, Korea Research Institute of Standards and \\ Science, Daejeon 305-600, Korea
}

\begin{abstract}
We have investigated the low-temperature cure process to realize nanoporous organosilicate thin films at temperature below $150{ }^{\circ} \mathrm{C}$ by adding a small amount of photoacid generator (PAG) followed by UV irradiation. The Gemini surfactant, which decomposes in the temperature range from 170 to $420^{\circ} \mathrm{C}$, was used as a pore-generating material (porogen) for organosilicate matrix. The UV pretreatment in the presence of PAG lowers the condensation temperature of poly(methyl silsesquioxane) matrix and leads to the fast matrix vitrification enabling the addition of increased amount of porogens. Because the full vitrification of the matrix $\left(150^{\circ} \mathrm{C}\right)$ by UV pretreatment in the presence of PAG below the decomposition temperature of porogens $\left(170^{\circ} \mathrm{C}\right)$ prevents the pore collapse, the porosity up to $35.5 \%$ was achieved with an average pore size of $3.4 \mathrm{~nm}$, as measured from X-ray reflectivity as well as ellipsometric porosimetry. It is shown that both dielectric constant and refractive index continue to decrease to 2.0 and 1.26 , respectively. The present experimental system demonstrates that porogens with low degradation temperature can be successfully incorporated to realize nanoporous films without pore collapse. Consequently, this process can widen the choice of porogens to prepare nanoporous films.
\end{abstract}

(C) 2007 The Electrochemical Society. [DOI: 10.1149/1.2741181] All rights reserved.

Manuscript submitted December 20, 2006; revised manuscript received March 21, 2007. Available electronically May 31, 2007.

In the International Technology Roadmap for Semiconductors (ITRS), new low dielectric materials below 2.1 in bulk dielectric constant are required to minimize the interconnect delay caused by high density of devices and wirings for high-performance semiconductor chips. ${ }^{1}$ Among many candidates for ultralow dielectric materials, nanoporous organosilicate thin films are one of the promising candidate materials, because their dielectric constant can be continuously reduced by the incorporation of nanopores within the films. Various nanoporous low dielectric films have been realized using poly(methyl silsesquioxane) (PMSSQ) as a matrix material incorporating many kinds of pore-generating materials (porogens) such as star-shaped polymers, ${ }^{2,3}$ block copolymers, ${ }^{4,5}$ cyclodextrins, ${ }^{6-8}$ norbornenes, ${ }^{9,10}$ dendrimers, ${ }^{11,12}$ and hybrid-type porogens. ${ }^{13}$ To achieve nanoporous structure without pore collapse, one of the key factors in selecting a relevant porogen is the degradation temperature. The porogens used in previous studies were chosen or synthesized to decompose at temperatures much higher than the temperature for matrix vitrification. Another important factor would be the miscibility between a matrix and a porogen to realize nanopores within the films with small size even at high porosity. Improved miscibility with a matrix material has been achieved by the chemical modification of end functional groups ${ }^{6}$ or end capping ${ }^{12}$ of porogens. However, the control over the degradation temperature of porogens still remains difficult because the inherent chemical structure should be altered.

In the present study, we employed the Gemini surfactant (GS) as a new porogen which contains two hydrocarbon tails to generate nanopores and a head group of hexamethytrisiloxane to improve the miscibility with an organosilicate matrix. Recently, the GS has successfully been utilized to realize mesoporous titanium oxides. ${ }^{14} \mathrm{Be}-$ cause the degradation temperatures of the GS porogens are not high enough when compared with the vitrification temperature of the matrix, the pores generated by the GS porogens frequently collapse during the matrix curing. Here, we applied the UV-assisted lowtemperature cure process in the presence of PAG to vitrificate the organosilicate matrix below the degradation temperature of GS to avoid the massive pore collapse. The PAG is known to accelerate the matrix condensation by generating superacid after UV irradiation ${ }^{15,16}$ and, as a result, over $80 \%$ of condensation in the matrix is achieved at $150^{\circ} \mathrm{C}$. The nanoporous low- $k$ thin films with dielectric constant $(k)$ around 2.0 are successfully realized by the low-

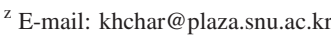

temperature matrix cure process with the PMSSQ matrix/GS porogen pair.

\section{Experimental}

Materials.-A PMSSQ copolymer used as a matrix material to realize nanoporous thin films was synthesized by the sol-gel reaction with methyltrimethoxysilane (MTMS, Aldrich) and 1,2-bis(trimethoxysilyl)ethane (BTMSE, Aldrich). ${ }^{17}$ The feed ratio between MTMS and BTMSE was $90 \mathrm{~mol} \%$ of MTMS and $10 \mathrm{~mol} \%$ of BTMSE. The PMSSQ copolymer prepared contains $25 \%$ of $\mathrm{Si}-\mathrm{OH}$ groups per silicon atom, as confirmed by ${ }^{1} \mathrm{H}-\mathrm{NMR}$. The Gemini surfactant $\left\{\mathrm{C}_{18} \mathrm{H}_{37} \mathrm{~N}\left(\mathrm{CH}_{3}\right)_{2}\left(\mathrm{CH}_{2}\right)_{3} \mathrm{O}\left[\mathrm{Si}\left(\mathrm{CH}_{3}\right)_{2} \mathrm{O}\right]_{3}\left(\mathrm{CH}_{2}\right)_{3} \mathrm{~N}\left(\mathrm{CH}_{3}\right)_{2} \mathrm{C}_{18} \mathrm{H}_{37} \mathrm{Br}_{2}\right\}$ employed as porogens to realize nanopores within the films was prepared by the reaction of 1,5-dibromopropoxyhexamethyltrisiloxane and octadecyldimethylamine, as previously described elsewhere. ${ }^{14}$ The photoacid generator (PAG), triphenylsulfonium trifluoromethanesulfonate, ${ }^{18}$ was purchased from Hayashi Pure Chemical. Mixtures of PMSSQ copolymer/GS porogen (90/10, $80 / 20,70 / 30$, and $60 / 40$ by weight) dissolved in 1-butanol were spin-coated onto piranha treated silicon wafers at $3000 \mathrm{rpm}$ for $30 \mathrm{~s}$. For UV irradiation, two UV lamps (Sankyo Denki) with the peak wavelength around $254 \mathrm{~nm}$ were used. The UV dosage was $2.8 \mathrm{~mW} / \mathrm{cm}^{2}$ at a distance of $10 \mathrm{~cm}$ vertically from the lamps.

Characterization.- Refractive indexes and film thicknesses of nanoporous thin films prepared were measured by an ellipsometer (L116B-85B, Gaertner sci). For the measurement of absolute porosity, X-ray reflectivity experiments were carried out at the $3 \mathrm{C} 2$ beam line of Pohang Light Source (PLS). Film thickness, which is about $500 \mathrm{~nm}$ equivalent to the thickness of one layer in multilayered low- $k$ applications, was too thick to measure with X-ray reflectivity, so the beam size was reduced down to the full-width at half maximum (fwhm) of $0.003^{\circ}$ and the wavelength of X-ray was $1.54 \AA$. To saturate the porous films with toluene vapor, a vacuum-sealed chamber with X-ray transparent windows was used. Pore size and pore size distribution of the nanopores within the films were estimated from the change in refractive index by varying the partial pressure of toluene using ellipsometric porosimetry. ${ }^{19}$ After measuring the adsorption and desorption isotherms of toluene with different partial pressures, the adsorbed and desorbed volume of toluene as a function of partial pressure were converted to the pore size and pore size distribution. A detailed description on this measurement is published elsewhere. ${ }^{19}$ Dielectric constants of nanoporous thin films were 

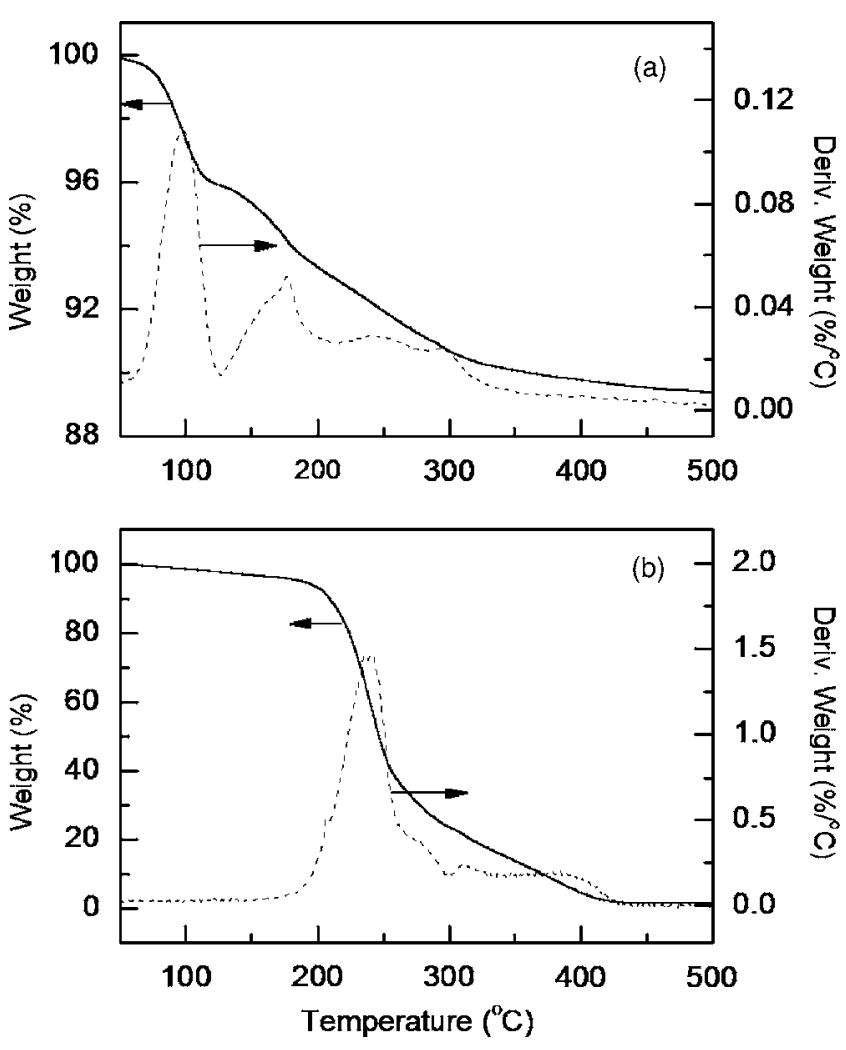

Figure 1. TGA traces of (a) a PMSSQ copolymer used in present study and (b) a Gemini surfactant used as a pore-generating material.

measured with a dielectric analyzer in metal-insulator-metal configuration at $1 \mathrm{MHz}$. For the measurement of dielectric constants, highly doped silicon wafers were used as bottom electrodes. Aluminum top electrodes were deposited onto nanoporous thin film surfaces with $1 \mathrm{~mm}$ diam using a thermal evaporator. Mechanical properties of nanoporous organosilicate thin films were obtained with depth-sensing indentation experiments using a Nanoinder XP (MTS Corp. ${ }^{20}$ A three-sided Berkovich diamond indenter was used for nanoindentation measurements. For the accurate measurement of apparent modulus $\left(E^{\prime}\right)$ as well as hardness $(H)$ for the porous thin films, dynamic contact module (MTS Corp.) was applied with fixed loading and unloading rates of $0.003 \mathrm{mN} / \mathrm{s}$.

\section{Results and Discussion}

To examine the thermal stability of organosilicate matrix material and GS porogens, TGA measurements were first performed. Figures 1a and $\mathrm{b}$ show the weight loss of the PMSSQ copolymer as well as GS porogens. Two significant weight losses of the PMSSQ copolymer were found at around 100 and $170^{\circ} \mathrm{C}$. The weight loss at $100^{\circ} \mathrm{C}$ is mainly attributed to the evaporation of residual water and casting solvent. Another weight loss at $170^{\circ} \mathrm{C}$ is caused by the condensation reaction between $\mathrm{Si}-\mathrm{OH}$ groups.

$\mathrm{Si}-\mathrm{OH}$ groups of the PMSSQ copolymer are estimated to be about $25 \%$ per silicon based on ${ }^{1} \mathrm{H}-\mathrm{NMR}$ data (not shown here). Because the PMSSQ copolymer consists of 10 mol \% BTMSE and $90 \mathrm{~mol} \%$ MTMS, the unit mass of the PMSSQ copolymer before cure is expected as 76.0 with 1.1 silicons per one average unit. When BTMSE $\left(\mathrm{O}_{1.5} \mathrm{SiCH}_{2} \mathrm{CH}_{2} \mathrm{SiO}_{1.5}\right)$ and MTMS $\left(\mathrm{CH}_{3} \mathrm{SiO}_{1.5}\right)$ are fully condensed after cure, the weight of each unit is 132 and 67, respectively, and thus the calculated unit mass of the PMSSQ copolymer is 73.5. As a result, the calculated percent weight loss after full condensation is $3.3 \%$, which is qualitatively the same as our TGA data shown in Fig. 1a indicating the $3.1 \%$ weight loss mea-
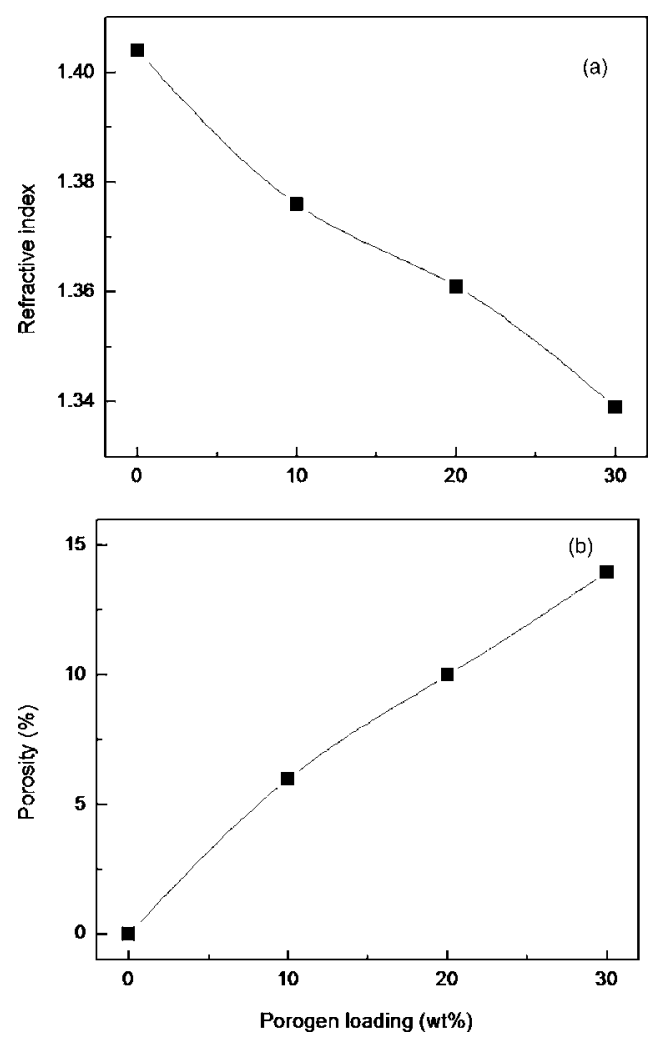

Figure 2. (a) Refractive indexes and (b) relative porosities of porous films prepared with GS without PAG.

sured from 110 to $210^{\circ} \mathrm{C}$. Noted also there is an additional $3.6 \%$ of weight loss in the high temperature window above $210^{\circ} \mathrm{C}$, which will be discussed below.

In the case of GS porogens, the molecular weight is 1076 with two grafted hydrocarbon chains $\left[2 \times\left(\mathrm{CH}_{2}\right)_{17} \mathrm{CH}_{3}\right]$ and thus the weight fraction of the degradable unit is estimated to be $47 \%$. This is also in good agreement with the experimental value of $50 \%$ weight loss in the temperature window ranging from 170 to $250^{\circ} \mathrm{C}$, as shown in Fig. 1b. We also note that because the onset temperature of GS degradation is around $170^{\circ} \mathrm{C}$, the matrix material should be fully vitrified at temperatures below $170^{\circ} \mathrm{C}$ to create pores within the films without extensive pore collapse.

Porous low- $k$ films were prepared using the GS porogens by varying porogen loading (10/90, 20/80, 30/70 GS/PMSSQ by weight). As mentioned above, to prevent possible pore collapse, the spun-cast films were initially cured at $150^{\circ} \mathrm{C}$ for $2 \mathrm{~h}$ followed by the additional heating protocol to ramp up to $450^{\circ} \mathrm{C}$ with a heating rate of $3{ }^{\circ} \mathrm{C} / \mathrm{min}$. The organosilicate films were then calcined at $450^{\circ} \mathrm{C}$ for $1 \mathrm{~h}$ to remove the porogens. The refractive index of each film was measured by ellipsometry, as shown in Fig. 2a. Based on the measured refractive indexes, relative porosities were also estimated using the Lorentz-Lorenz equation, as represented in Fig. 2b. The measured refractive index of the cured PMSSQ copolymer film without GS porogen was 1.404 and the refractive index of porous films gradually decreases with the increase in GS porogen loading. Calculated porosity of each porous film with 10,20 , and $30 \mathrm{wt} \%$ GS porogen loadings is 6,10 , and $14 \%$, respectively. Because the estimated porosity turns out to be lower than the actual loading amount of the porogens, the low-temperature cure at $150^{\circ} \mathrm{C}$ is not enough to guarantee the full condensation of the PMSSQ copolymer to avoid possible pore collapse. The measured dielectric constant $(k)$ is 2.80 (without GS), 2.69 (with $10 \mathrm{wt} \%$ GS porogens), 2.43 (with $20 \mathrm{wt} \%$ GS porogens), and 2.40 (with $30 \mathrm{wt} \%$ GS porogens). Note that with higher GS loadings above $30 \mathrm{wt} \%$, the refractive index 

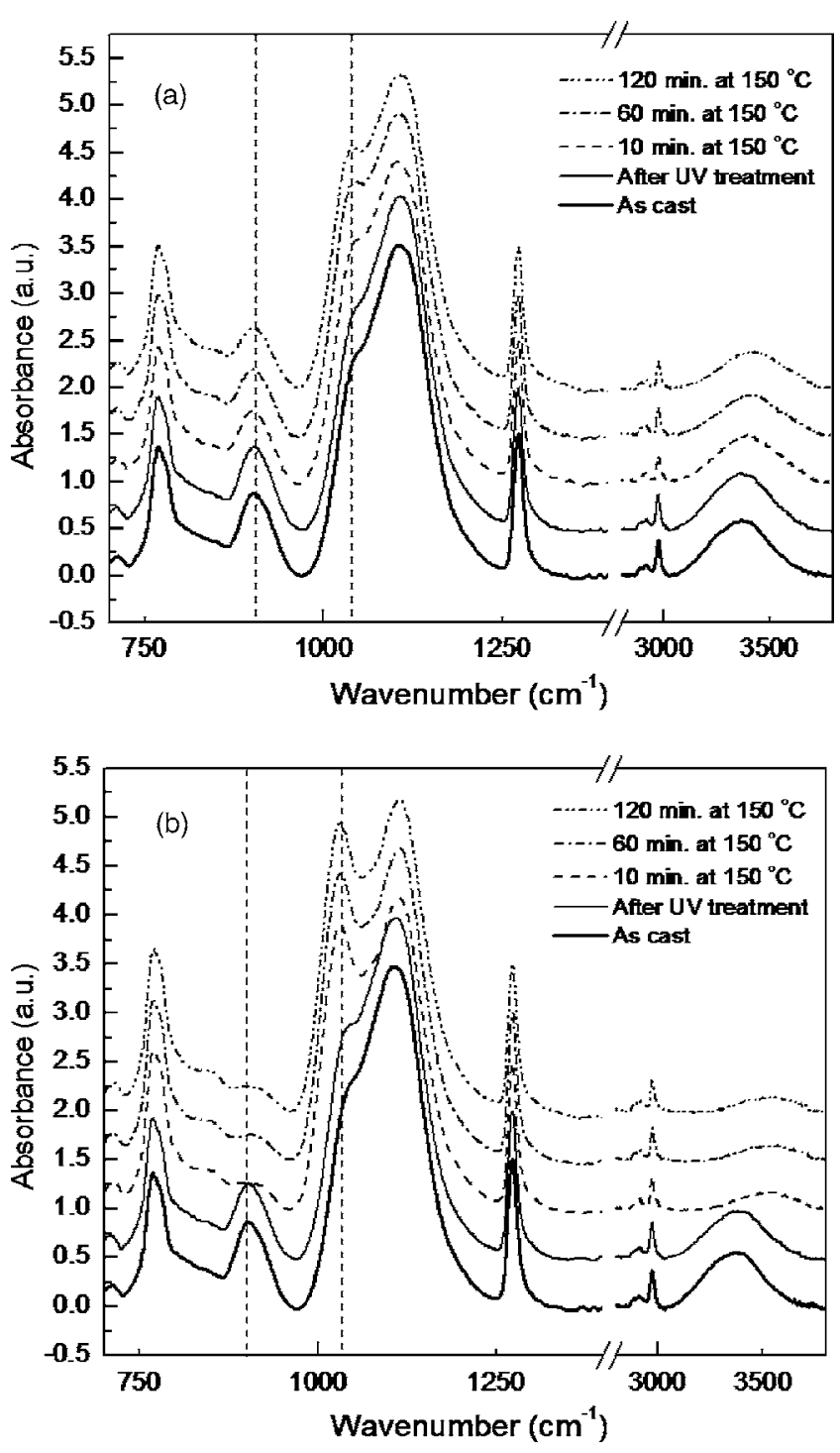

Figure 3. FTIR spectra for PMSSQ copolymer films (a) without PAG and (b) with 1 wt $\%$ PAG annealed at $150^{\circ} \mathrm{C}$ for 10,60 , and $120 \mathrm{~min}$.

measurement was not possible for cured films due to rough surfaces originating from the dominant porogen collapse, implying that the low- $k$ films with $k$ lower than 2.4 are not possible with the PMSSQ/GS mixture system alone.

We investigated the degree of condensation of PMSSQ copolymer cured at $150^{\circ} \mathrm{C}$ at different time using Fourier transform infrared spectroscopy (FTIR). As shown in Fig. 3a, the as-cast film shows the $\mathrm{Si}-\mathrm{C}$ vibration at $768 \mathrm{~cm}^{-1}, \mathrm{Si}-\mathrm{OH}$ vibration at $902 \mathrm{~cm}^{-1}, \mathrm{Si}-\mathrm{O}-\mathrm{Si}$ asymmetric vibration at $1105 \mathrm{~cm}^{-1}, \mathrm{Si}-\mathrm{CH}_{3}$ deformation at $1270 \mathrm{~cm}^{-1}$, and $\mathrm{OH}$ vibration at $3360 \mathrm{~cm}^{-1}$. After UV treatment for $10 \mathrm{~min}$ in the absence of PAG, no significant change in the FTIR spectrum was observed. When the films were cured at $150^{\circ} \mathrm{C}$ for $10 \mathrm{~min}$, the $\mathrm{Si}-\mathrm{OH}$ vibration and $\mathrm{OH}$ vibration peaks marginally decrease and, at the same time, the vibration peak at $1030 \mathrm{~cm}^{-1}$, corresponding to the $\mathrm{Si}-\mathrm{O}-\mathrm{Si}$ network structure, increases due to the condensation reaction between $\mathrm{Si}-\mathrm{OH}$ groups. When the cure time is increased from 60 to $120 \mathrm{~min}$, the peak area of $\mathrm{Si}-\mathrm{OH}$ vibration at $902 \mathrm{~cm}^{-1}$ relative to that of as-cast film gradually decreases to 81,74 , and $64 \%$, respectively, implying that the matrix condensation at $150{ }^{\circ} \mathrm{C}$ is not extensive enough to prevent pore collapse. As a result, as shown in Fig. 2, the porous films containing GS porogens show lower porosity than initially expected.
To find good use in low-temperature degradable porogens such as GS porogens, the matrix condensation temperature should inevitably be lowered. To accelerate the matrix condensation at low process temperatures, one possible way is to use an acid or base catalyst as a curing agent. However, that kind of catalyst is not a good candidate because it accelerates the matrix condensation so fast in ambient condition that the controlled curing is not possible, creating problems in storage. In the present study, we used a PAG to bring down the matrix condensation temperature because it has been known that the PAG generates acid upon UV irradiation. When $1 \mathrm{wt} \%$ of PAG was added to the PMSSQ copolymer and UV irradiation was performed on the films at the dosage of $2.8 \mathrm{~mW} / \mathrm{cm}^{2}$, the FTIR spectra clearly showed the effective matrix condensation at low cure temperature such as $150^{\circ} \mathrm{C}$, as verified in Fig. 3b. Upon UV irradiation for $10 \mathrm{~min}$, the $\mathrm{Si}-\mathrm{OH}$ vibration peak reduced to $83 \%$ due to the structural change in the PMSSQ copolymer due to the acid generated. During thermal cure at $150^{\circ} \mathrm{C}$, the facile condensation among $\mathrm{Si}-\mathrm{OH}$ groups occurs within $10 \mathrm{~min}$ and only $15 \%$ of $\mathrm{Si}-\mathrm{OH}$ groups remain. Upon a further increase in cure time to 60 and $120 \mathrm{~min}$, the amount of residual $\mathrm{Si}-\mathrm{OH}$ groups is further decreased to $13 \%$, implying that the $\mathrm{Si}-\mathrm{OH}$ condensation almost levels off at around $10 \mathrm{~min}$ of cure at $150^{\circ} \mathrm{C}$. Concurrently with the condensation of $\mathrm{Si}-\mathrm{OH}$ groups, the $\mathrm{Si}-\mathrm{O}-\mathrm{Si}$ network structure is also extensively formed, as demonstrated in the increase of $\mathrm{Si}-\mathrm{O}-\mathrm{Si}$ vibration peak at $1030 \mathrm{~cm}^{-1}$ within $10 \mathrm{~min}$.

Note that when the PMSSQ copolymer is cured at $450^{\circ} \mathrm{C}$ with or without PAG, the refractive indexes of those two cases are different; 1.381 with PAG and 1.404 without PAG. Note also that the dielectric constant of the PMSSQ copolymer with and without PAG was measured to be 2.68 and 2.80 , respectively. This implies that the film properties were also altered by adding PAG even before porogens are added. To find the clue for the difference in both refractive index and dielectric constant, FTIR experiments were carried out. After thermal cure at $450^{\circ} \mathrm{C}$, as shown in Fig. $4 \mathrm{a}$, the film containing PAG has a slightly higher peak at $1130 \mathrm{~cm}^{-1}$, which is assigned to the cagelike structure of MSSQ, than the film without PAG. In the case of the film without PAG, when we compare the FTIR spectra of as-cast film with that of the film after thermal cure, the area under the $\mathrm{Si}-\mathrm{CH}_{3}$ deformation peak at $1270 \mathrm{~cm}^{-1}$ decreases by $10 \%$ upon cure, as shown in Fig. 4b. On the other hand, with the film containing PAG, the area under the $\mathrm{Si}-\mathrm{CH}_{3}$ deformation peak at $1270 \mathrm{~cm}^{-1}$ almost remains the same, as evidenced in Fig. 4c. The experimental data suggest that the cagelike structure of PMSSQ copolymer evaporates during the thermal cure without PAG while the MSSQ cages are trapped by doping PAG into the film because the acid generated by PAG facilitates the matrix condensation. Additionally, the trapped cages contribute to the formation of micropores within the PMSSQ copolymer film, resulting in low refractive index and dielectric constant. Additional indirect evidence to support this explanation can be found in the change of film thickness after cure. Without PAG, the film thickness after cure was reduced by $13 \%$ relative to the thickness of as-cast film while the film containing 1 wt $\%$ PAG shows only $9 \%$ decrease in the film thickness after thermal cure. This implies that the evaporation of cagelike PMSSQ structure is about 4\%, which is in good agreement with the TGA traces in Fig. 1a of the additional weight loss of $3.6 \%$ above $210^{\circ} \mathrm{C}$.

We successfully lowered the condensation temperature as well as the starting dielectric constant of the PMSSQ copolymer with the aid of PAG followed by UV treatment, which makes possible the vitrification of the PMSSQ copolymer below the degradation temperature of GS porogens. To confirm this low-temperature cure for the matrix, films of PMSSQ copolymer/1 wt \% PAG with varying GS porogen loading (90/10, 80/20, 70/30, and $60 / 40$ by weight) were prepared. Prepared films were pretreated with UV for $10 \mathrm{~min}$ and then cured at $150^{\circ} \mathrm{C}$ for $2 \mathrm{~h}$ under vacuum, followed by final calcination at $450^{\circ} \mathrm{C}$ for $1 \mathrm{~h}$ under nitrogen to yield porous thin films.

The change in refractive index of nanoporous films with different GS porogen loading is shown in Fig. 5a. With the increase in poro- 

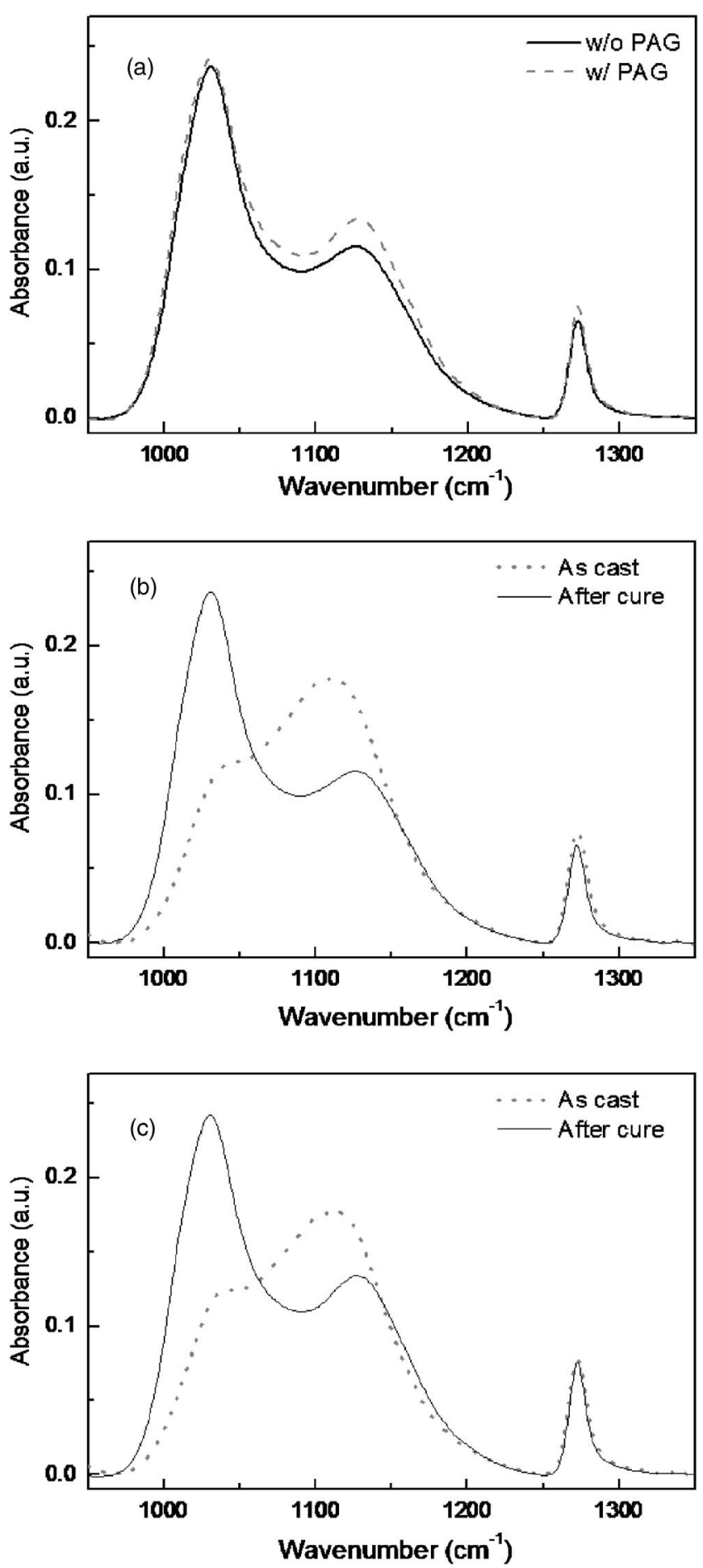

Figure 4. FTIR spectra of PMSSQ copolymer films after cure (a) with PAG and without PAG, (b) as-cast and cured films without PAG, and (c) as-cast and cured films with PAG.

gen loading, the refractive index gradually decreases. We found that the refractive index continues to decrease down to 1.255 when $40 \mathrm{wt} \%$ porogens are added. We emphasize at this point that the nanoporous thin films with smooth surface are only possible with the presence of PAG in the matrix for porogen loading higher than $40 \mathrm{wt} \%$. As shown in Fig. 5b, the estimated relative porosity is $2 \%$, $13 \%, 22 \%$, and $31 \%$ for the porogen loadings of $10,20,30$, and $40 \mathrm{wt} \%$, respectively. This implies that porous films prepared in the presence of PAG have higher porosity compared with the films in
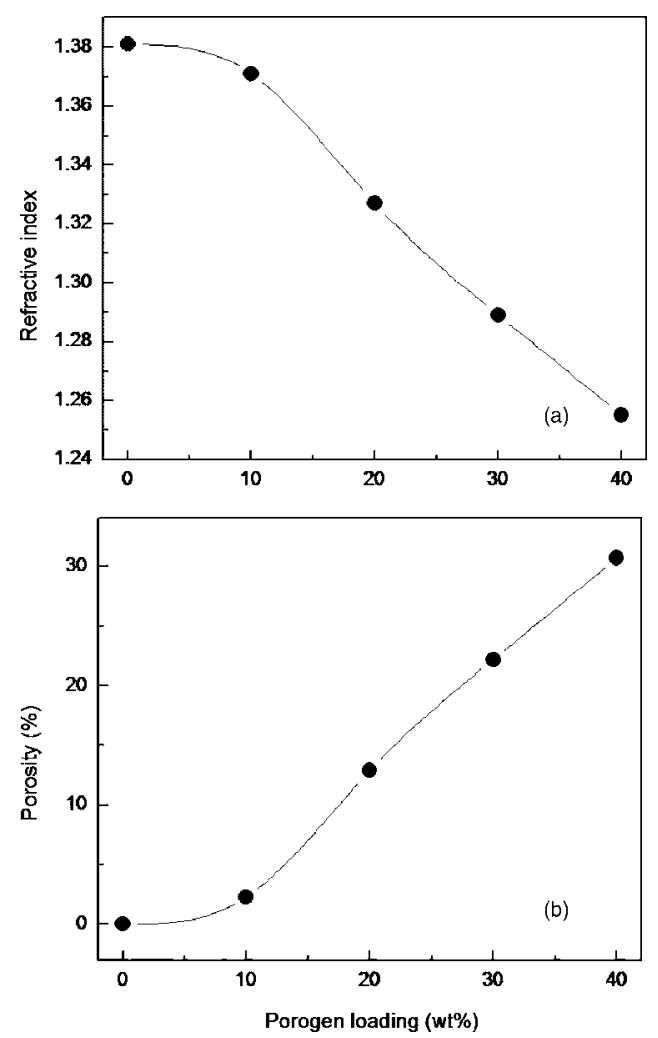

Figure 5. (a) Refractive indexes and (b) relative porosities of porous films prepared with GS with PAG.

the absence of PAG (Fig. 2) because the addition of PAG and further UV treatment decrease the matrix condensation temperature, preventing pore collapse during thermal cure at higher temperatures.

To obtain information on the absolute porosity of porous films, $\mathrm{X}$-ray reflectivity experiments were carried out under air as well as in toluene saturation environment. Figure 6 shows experimental X-ray reflectivity curves as a function of $q\left[q=(4 \pi / \lambda) \sin \theta, \AA^{-1}\right]$ with different porogen loading $(0,10,20,30$, and $40 \mathrm{wt} \%)$. It has

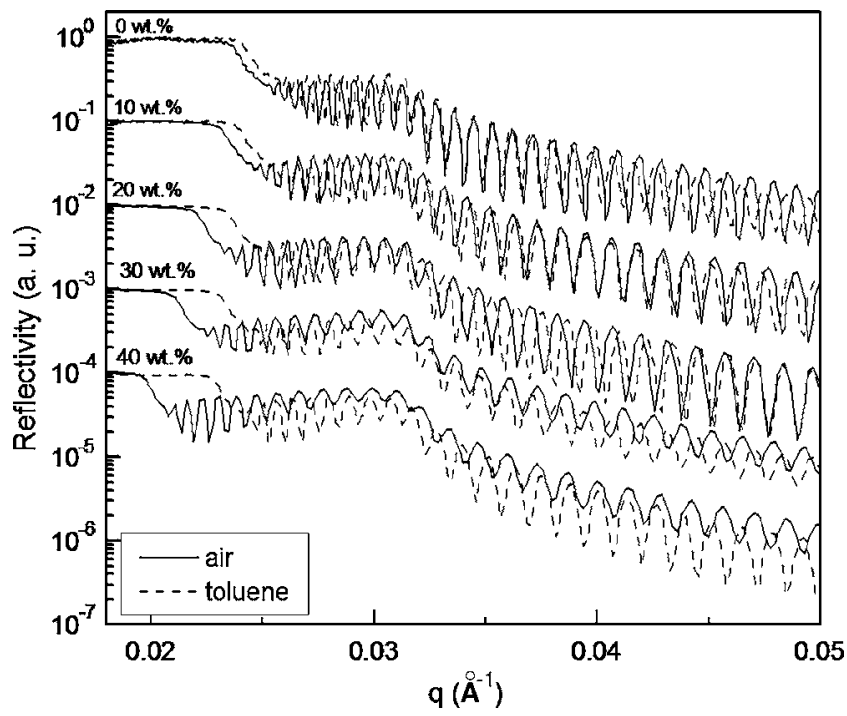

Figure 6. X-ray reflectivity curves for nanoporous films with different porogen loadings. To obtain the absolute porosity of the porous films, X-ray reflectivity measurements were performed under ambient and also in toluene saturation environment. 
been well known that the critical angle, at which grazing X-ray beam starts to penetrate into the film and the reflectivity drops sharply, is related to the average electron density of the film as follows

$$
\theta_{c}=\lambda\left(\rho_{e} r_{e} / \pi\right)^{0.5}
$$

where $\rho_{e}$ is the average electron density and $r_{e}$ is the classical radius of an electron. Measured average electron density $\left(e^{-} / \mathrm{cm}^{3}\right)$ was converted to the density of a film $\left(\mathrm{g} / \mathrm{cm}^{3}\right)$ based on the theoretical atomic compositions of Si:O:C:H (15.8: 23.8: 15.8: 44.6).

The equations for film density with and without toluene sorption in the film are given as follows ${ }^{21-23}$

$$
\begin{gathered}
\rho_{\text {air }}=\rho_{\text {wall }}(1-P) \\
\rho_{\text {saturated }}=\rho_{\text {wall }}(1-P)+\rho_{\text {toluene }} P
\end{gathered}
$$

where $\rho_{\text {air }}, \rho_{\text {wall }}, \rho_{\text {saturated }}$, and $\rho_{\text {toluene }}$ are the film density measured in air, the density of wall material separating pores, the film density measured in toluene saturation environment, and the density of toluene, respectively.

As expected, the critical angles for porous films without toluene sorption decrease with the increase in porosity due to the reduction of film density. Upon toluene treatment, for which toluene vapor readily diffuses into accessible pores within films by capillary condensation, the gap in two critical angles (with and without toluene sorption) increases with the increase in porosity.

The calculated porosities $(P)$ based on Eq. 2 and 3 are summarized in Table I. Compared with calculated relative porosity, as shown in Fig. 5, the absolute porosity measured by X-ray reflectivity shows a higher value because the toluene vapor fills up the pores generated by calcining out the porogens as well as the inherent micropores of the PMSSQ copolymer.

To gain information on the pore size and pore size distribution which are one of the important pieces of information on nanoporous low- $k$ dielectric layers, ellipsometric porosimetry experiments were carried out for porous films prepared with 30 and $40 \mathrm{wt} \%$ of porogen loadings. The adsorption isotherms with toluene vapor are shown in Fig. 7a and b. From the toluene desorption trace, the pore radius distribution was calculated, as shown in Fig. 7c and d. Both porous films indicate the two desorption modes corresponding to pore radii of 0.9 and $1.7 \mathrm{~nm}$. Because the PMSSQ copolymer itself has an absolute porosity of $5.9 \%$, as measured from X-ray reflectivity, the small pores with a radius of $0.9 \mathrm{~nm}$ are believed to originate from the inherent micropore structure of the PMSSQ copolymer. The larger pores with a radius of $1.7 \mathrm{~nm}$ are then assigned to the pores generated by the calcination of porogens. Note that regardless of the porogen loading up to $40 \mathrm{wt} \%$, the two different pore sizes within the films are almost constant, implying the effective suppression of pore collapse with the aid of UV treatment in the presence of PAG in the films.

Finally, the dielectric constant of prepared porous films was measured and also listed in Table I. Dielectric constant of the PMSSQ copolymer itself without porogens is 2.68 and the dielectric constant gradually decreases down to 2.00 with increasing the porogen loading up to $40 \mathrm{wt} \%$. In addition, the modulus and hardness were also measured to study the effect of porous structure on the mechanical properties of low- $k$ films. Loading rate was optimized to obtain intrinsic mechanical properties of low- $k$ films excluding the substrate effect and thus a loading rate of $0.003 \mathrm{mN} / \mathrm{s}$ was applied. To ex-
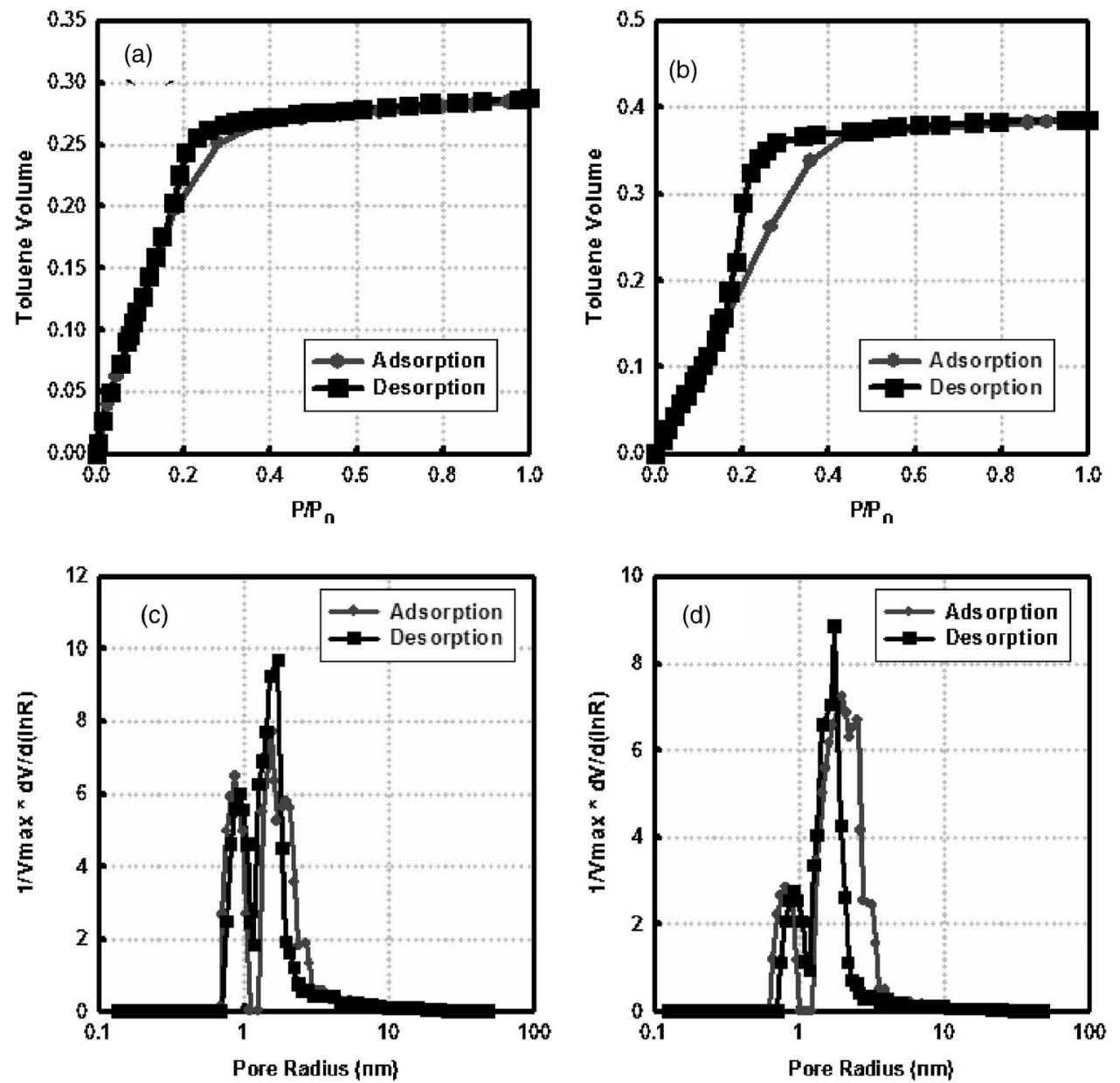

Figure 7. Toluene adsorption isotherms of nanoporous films for (a) 30 and (b) $40 \mathrm{wt} \%$ of GS porogen loadings. Pore size distribution is also estimated based on the toluene desorption isotherm for (c) 30 and (d) $40 \mathrm{wt} \%$ of porogen loadings. 


\begin{tabular}{|c|c|c|c|c|}
\hline Porogen loading (wt \%) & $k$ & $E^{\prime}(\mathrm{GPa})$ & $H(\mathrm{GPa})$ & $P(\%)^{\mathrm{a}}$ \\
\hline 0 & 2.68 & 4.32 & 0.563 & 5.9 \\
\hline 10 & 2.62 & 4.23 & 0.546 & 9.3 \\
\hline 20 & 2.37 & 3.16 & 0.395 & 17.5 \\
\hline 30 & 2.16 & 2.03 & 0.239 & 23.8 \\
\hline 40 & 2.00 & 1.27 & 0.126 & 35.5 \\
\hline
\end{tabular}

clude the substrate effect, apparent modulus and hardness values were extracted at a normalized depth of 0.05 and these values are summarized in Table I. Note that the apparent modulus and hardness values decrease with the increase in porosity because pores introduced within the films reduce the density of MSSQ copolymer films.

\section{Conclusions}

We investigated the low-temperature condensation process of organosilicate matrix thin films by the addition of PAG followed by UV pretreatment. The introduction of 1 wt $\%$ of PAG into the film was effective to facilitate the $\mathrm{Si}-\mathrm{OH}$ condensation. Fast condensation of the matrix locks up the GS porogens before their degradation, resulting in high porosity $(P \sim 36 \%)$ with a small pore size of about $3.4 \mathrm{~nm}$ and expanding the upper limit of porogen loading without pore collapse. With this matrix treatment process, the porogens with low degradation temperature $\left(<200^{\circ} \mathrm{C}\right)$, such as GS porogens, were successfully applied to realize nanoporous ultralow dielectric thin films $(k \sim 2.0)$ and the dielectric constant of the PMSSQ copolymer itself was also lowered by containing more cages within the film due to the UV treatment. This process allowed us to widen the choice of porogens to realize nanopores within organosilicate films because nanoporous films can be obtained without controlling the degradation temperature of porogens simply by lowering the matrix condensation temperature.

\section{Acknowledgments}

This work was supported by the NANO Systems InstituteNational Core Research Center (NSI-NCRC) of the Korea Science and Engineering Foundation (KOSEF), the Brain Korea 21 Program endorsed by the Ministry of Education of Korea, and "System IC 2010" Project of Korea Ministry of Commerce, Industry and Energy.
We are very grateful to B. H. Seung and Y. J. Park at POSTECH for their assistance during X-ray reflectivity experiments at Pohang Light Source (PLS) supported by the Ministry of Science and Technology of Korea. article.

Seoul National University assisted in meeting the publication costs of this

\section{References}

1. The International Technology Roadmap for Semiconductors, Semiconductor Industry Association, San Jose, CA (2001).

2. C. V. Nguyen, K. R. Carter, C. J. Hawker, J. L. Hedrick, R. L. Jaffe, R. D. Miller, J. F. Remenar, H. W. Rhee, P. M. Rice, M. F. Toney, M. Trollsas, and D. Y. Yoon, Chem. Mater, 11, 3080 (1999).

3. Y. Toivola, S. Kim, R. F. Cook, K. Char, J. K. Lee, D. Y. Yoon, H. W. Rhee, S. Y. Kim, and M. Y. Jin, J. Electrochem. Soc., 151, F45 (2004).

4. Q. R. Huang, W. Volksen, E. Huang, M. Toney, C. W. Frank, and R. D. Miller, Chem. Mater, 14, 3676 (2002)

5. S. Yang, P. A. Mirau, C. S. Pai, O. Nalamasu, E. Reichmanis, J. C. Pai, Y. S. Obeng, J. Seputro, E. K. Lin, H. J. Lee, J. N. Sun, and D. W. Gidley, Chem. Mater, 14, 369 (2002)

6. J. H. Yim, Y. Y. Lyu, H. D. Jeong, S. A. Song, I. S. Hwang, J. Hyeon-Lee, S. K. Mah, S. Chang, J. G. Park, Y. F. Hu, J. N. Sun, and D. V. Gidley, Adv. Funct. Mater, 13, 382 (2003).

7. J. H. Yim, M. R. Baklanov, D. W. Gidley, H. G. Peng, H. D. Jeong, and L. S. Pu, J. Phys. Chem. B, 108, 8953 (2004)

8. J. H. Yim, J. B. Seon, T. D. Jeong, L. S. Pu, M. R. Baklanov, and D. W. Gidley, Adv. Funct. Mater., 14, 277 (2004).

9. A. M. Padovani, L. Rhodes, S. A. B. Allen, and P. A. Kohl, J. Electrochem. Soc., 149, F161 (2002).

10. A. M. Padovani, L. Rhodes, S. A. B. Allen, and P. A. Kohl, J. Electrochem. Soc., 149, F171 (2002).

11. S. Z. Yu, T. K. S. Wong, X. Hu, K. Pita, and V. Ligatchev, J. Electrochem. Soc., 151, F123 (2004)

12. B. D. Lee, Y. H. Park, Y. T. Hwang, W. Oh, J. Yoon, and M. Ree, Nat. Mater, 4 147 (2005)

13. H. W. Ro, K. J. Kim, P. Theato, D. W. Gidley, and D. Y. Yoon, Macromolecules, 38, 1031 (2005).

14. Y. Y. Lyu, S. H. Yi, J. K. Shon, S. Chang, L. S. Pu, S. Y. Lee, J. E. Yie, K. Char, G. D. Stucky, and J. M. Kim, J. Am. Chem. Soc., 126, 2310 (2004).

15. A. S. Gozdz, Polym. Adv. Technol., 5, 70 (1994).

16. C. J. Brinker and G. W. Scherer, Sol-Gel Science: The Physics and Chemistry of Sol-Gel Processing, Academic Press, San Diego (1990).

17. S. Kim, Y. Toivola, R. F. Cook, K. Char, S. H. Chu, J. K. Lee, D. Y. Yoon, and H W. Rhee, J. Electrochem. Soc., 151, F37 (2004).

18. J. L. Dektar and N. P. Hacker, J. Am. Chem. Soc., 112, 6004 (1990).

19. M. R. Baklanov, K. P. Mogilnikov, V. G. Polovinkin, and F. N. Dultsev, J. Phys. Soc. Jpn., 18, 1385 (2000)

20. W. C. Oliver and G. M. Pharr, J. Mater. Res., 7, 1564 (1992).

21. H. J. Lee, C. L. Soles, D. W. Liu, B. J. Bauer, and W. L. Wu, J. Polym. Sci., Part B: Polym. Phys., 40, 2170 (2002)

22. H. J. Lee, C. L. Soles, D. W. Liu, B. J. Bauer, E. K. Lin, W. L. Wu, and A. Grill, J. Appl. Phys., 95, 2355 (2004).

23. C. L. Soles, H. J. Lee, R. C. Hedden, D. W. Liu, B. J. Bauer, and W. L. Wu, Polym Microelectron. Nanoelectron., 874, 209 (2004). 